\title{
Participatory Research Challenges in Drug Abuse Studies Among Transnational Mexican Migrants
}

\author{
Victor Garcia*,1 and Laura Gonzalez $^{2}$ \\ ${ }^{I}$ Department of Anthropology, Indiana University of Pennsylvania, Indiana, Pennsylvania, USA
${ }^{2}$ Mid-Atlantic Research and Training Institute, Indiana University of Pennsylvania, Indiana, Pennsylvania, USA
}

\begin{abstract}
Participatory research is essential in public health studies, but using this methodology to examine sensitive public health problems among vulnerable populations is a challenge. We share some of our trials and tribulations in attempting to use participatory research in our substance abuse studies among transnational Mexican migrants in southeastern Pennsylvania. Major challenges did not permit partnerships across the community in all phases of research, including the dissemination of findings. Especially difficult was including transnational migrants and nearby relatives as partners in the research, similar to partnerships created with others in the community. The sensitive nature of our research and associated human subject concerns did not permit a more participatory methodology. Another problem involved partnerships with members of the larger community, given the apathy and ambivalence towards drug use by transnational migrants. Finally, collaborating with community stakeholders to develop and implement research-based recommendations was also problematic. As we learned, there are more to generating substance abuse recommendations in partnership with stakeholders than simply working together on recommendations, which also require an effective implementation strategy. Based on these experiences, we elaborate useful suggestions in development and application of local-level programs aimed at curtailing substance abuse among transnational migrant workers while they are at their work sites in Pennsylvania.
\end{abstract}

Keywords: Participatory research, transnational migrants, agricultural labor, drug abuse, health care.

\section{INTRODUCTION}

Participatory research, also known as "participatory action research," "community-based research," and "advocacy research," is changing the way that public health research is conducted among vulnerable populations in the United States. A basic definition of this research approach, one that captures its important underlying principles, characterizes it as a "systematic enquiry in collaboration with those affected by the issue being studied for the purpose of education and taking action or effecting social change" [1]. Participatory research departs from conventional forms of research in that a community -its residents and stakeholders-are treated as research partners. ${ }^{i}$ That is, they have a say in the research, not as passive research subjects answering survey questions, but as active research collaborators making suggestions as to what needs to be studied, assisting in making inroads into the community and developing crucial rapport and trust, and explaining how findings can be used to benefit them directly. In this non-conventional research approach, the researcher

*Address correspondence to this author at the Department of Anthropology, Indiana University of Pennsylvania, Indian, Pennsylvania, USA;

Tel: (724) 357-1240; Fax: (724) 357-3944; E-mail: vgarcia@iup.edu

${ }^{\mathrm{i}}$ In this article, "community" refers to physical and social space, defined by governmental sanctioned boundaries, and shared by local residents who reside, raise families, and worship in it, regardless of their citizenship, ownership of property, and length and permanency of residence. Transnational migrants are also members of the community, although they often are not recognized or treated as such. Community stakeholders are business, civic and religious leaders. In defining stakeholders in this fashion, we are well aware that in reality all community members, including those who are nonpermanent residents, have a stake in the well being of their communities. and the community, as a team, identify the problem together, devise a data gathering protocol, and generate findings needed to solve an immediate community problem. In short, participatory research includes the community as an active collaborator in all phases of research, from planning and implementation to the proposing of local-level programs and policies [2].

Despite its documented success in giving the voiceless a voice in indentifying and solving their health problems, we found a number of limitations in using participatory research in our investigation of substance abuse among transnational migrants (see Acknowledgments). Transnational farmworkers might work in the United States often for years at a time, but their permanent home base, where their families remain, is in Mexico. Three limitations in particular which do not permit successful use of participatory research with this population are introduced here and discussed in the following sections. One is the illegal nature of the drug use of the transnational migrants, which involves human subject concerns associated with drug use and, in some cases, immigration status of the migrants. The second is the general indifference of the community, including Mexican immigrant residents, towards the substance abuse problems of transnational migrants. The third involves partnerships with different community stakeholders in collaborating to make research recommendations. Working together, we came up with a set of social policy, prevention, and intervention program recommendations, only to later discover that they were not implemented. We learned that there is more to making research-based substance abuse recommendations in partnership with community-stakeholders than just developing them together. Recommendations must also be accompanied by an 
effective implementation strategy, which is no easy task for a number of reasons, which will be discussed later in this article. Based on our experiences, we provide suggestions that can be of use in other communities for making and implementing recommendations that are aimed at transnational migrant workers.

\section{PARTICIPATORY RESEARCH AND DRUG ABUSE RESEARCH AMONG TRANSNATIONAL MEXICAN MIGRANTS}

Increasingly, as the literature demonstrates, participatory research is becoming common in promoting health programs and healthy lifestyles [3-8]. It has proven useful in implementing substance abuse programs in communities with atrisk populations [9]. Without community participation of some kind, drug abuse programs with a focus on prevention and intervention are not successful. Many of the participatory research methods used in these studies, such as data gathering with sequential reflection and action, and making recommendations using local-level knowledge, are drawn from mainstream disciplines, such as anthropology and sociology. The literature does not include substance use among hidden or hard-to-reach populations, such as transnational Mexican migrants. In fact, a formal literature search did not identify any articles on use of some form of participatory research in substance abuse research among this labor force.

Our observations regarding the limitations of using participatory research in substance abuse studies are based on our drug abuse research in southeastern Pennsylvania and Mexico. In these studies, we were unable to use the participatory research approach that often accompanies our ethnographic fieldwork. Prior to this experience, as early as the research for our doctoral degrees in the late 1980s, we developed a community research approach that we would later learn was akin to participatory research [10]. At that time we did not initiate it because of the emerging participatory research literature; we did so because we discovered that our approach is a good way of conducting effective ethnographic research. We learned early in our training as anthropologists that in order to study a community and understand its pressing problems, one must reside locally, participate in community activities, regardless of whether they are related to the research subject or not, and include as many community stakeholders as possible to create local-level partnerships for gaining input from the community, and for developing research recommendations. In the 1990s, in our work as professional anthropologists, we continued to use a participatory research approach in our census, housing, and immigration studies and achieved a high level of participation from immigrant and migrant farmworkers and other segments of the local community, among them, growers and farm labor unions. We developed our research proposals according to the guidelines of the Request for Proposals of the funding agencies, and when time allowed, in consultation with key informants and other members of the community. In the field, we continued to seek community input in redefining the problem, if necessary, and local advice on how to use our findings to introduce effective change.

We found that including farmworkers and other community groups, particularly growers, faith-based groups, and community-based service providers, in research partnerships belayed the fears and dispelled rumors that flared once in a while, particularly suspicions that the researcher and his/her team were conducting intelligence gathering for local police or other governmental authorities, such as Immigration and Naturalization Service (INS), which became Immigration and Customs Enforcement (ICE). Getting the community at large involved also protects the safety of researchers in the field. Local residents keep the researchers abreast of any local developments that may place them in danger or that may put the research project in jeopardy.

In our drug studies, this degree of participation previously experienced was not possible with the transnational farmworker population or the larger community. We were only able to partner with community stakeholders that serve the local Mexican-origin population in the recommendation phase. A major stage of the research, which was locating and studying the transnational migrants, was not part of the collaboration. We relied on a traditional ethnographic approach, locating drug using and non-drug using key informants, often with the help of some community members, and employing observations, informal interviews, and intensive note taking, tools of the ethnographic endeavor. We learned a great deal from our key informants, particularly from their experiences and the concepts and the categories that defined them.

\section{DRUG ABUSE RESEARCH METHODOLOGY}

Over the last decade, we have completed two ethnographic studies on substance abuse among transnational migrants employed in the mushroom industry, and we are currently working on a third. One of our research projects was a study on problem drinking, conducted from 2000 to 2002 [11], and the other, a study on psychotropic drug use, started in 2004 and completed in 2006 [12]. The objective of the studies was two-fold: one, to describe the association between situational factors (e.g, living arrangements and social isolation) and problem drinking and drug abuse, and two, to explore the role of background/individual (e.g, demographic background and education level) and predisposing factors (e.g, previous alcohol and drug use and witnessing of drug use in Mexico or in U.S. urban areas) to substance abuse.

Throughout our studies, we lived on-site and gathered both community and individual-level data. Community ethnography was conducted to gain insights from migrants themselves and to learn about the local cultural context of alcohol and other drug use among these workers. Direct field observations, informal interviews with migrant workers and non-migrant community residents, focus group interviews, and the review of newspapers and other documents were used to gather community-level data. Using data obtained from the community ethnography, 12 to 16 migrants were selected from our key informants for more detailed study as case studies in order to substantiate and elaborate the role of number of factors in drug use. A case study approach is ideal when a holistic, in-depth investigation is employed and illustrates the specifics of general patterns and themes, and the variations of these generalizations among individuals or groups.

Two years ago, building on our earlier substance abuse investigations, we started a third ethnographic drug study-a bi-national study of drug use among this migrant population in both Pennsylvania and Guanajuato, Mexico. In its third 
and last year, the focus of study is the use of marijuana, cocaine, crack, and, to a lesser extent, amphetamines among transnational migrants. Drawing on the findings from our earlier studies, we identified and embarked on examining the relationships of factors associated with the migrants' transnational status, specifically, previous exposure to drug use, individual background characteristics, and situational factors (e.g, living and working conditions). The premise of our third study, as outlined in our model [13], was that the migrants', judicial immigration status in the country-as foreign solo men and, at times, unauthorized or undocumented/illegal workers-places them at risk for substance abuse. They live without families in relatively isolated farmworker housing compounds or overcrowded apartment units for years, and seldom visit immigrant kin in nearby communities because of the lack of time and transportation. Missing in these living situations are familial- and community-based deterrents to heavy drinking and drug use. As we [14] and other researchers [15-20] have described, these deterrents are kin and labor camp sanctions against substance abuse, presence of kin-based authority figures, and a familial support base. A demanding and heavy work schedule adds to the stress of these unconventional living arrangements, as Garcia [11, 12] and Bletzer [21] point out in their work. Additionally, the migrant workers are exposed to heavy alcohol consumption and drug use in U.S. work sites and in their hometowns in Mexico. Through this exposure, they learn to complement their drinking activities with drug use in order to cope with their plight.

These three substance abuse studies underwent a rigorous human subjects review at our home institution. The third study, given its bi-national nature, also included human subjects review at the National Institute of Psychiatry in Mexico City.

Our research focused on a transnational workforce of a major industry in the United States, the mushroom industry, and the home communities of the workers back in Mexico. The majority of the 4,000 or 50 estimated workers who harvest mushrooms are male transnational migrants whose permanent home base is in Mexico. The first large contingency of Mexican migrants to work in the industry arrived in the 1970s, primarily from the states of Guanajuato, Jalisco, and Mexico. They were the first to settle in the region with their families, illegally, or through government authorization after the Immigration Reform and Control Act of 1986. These early sojourners were later joined by compatriots from Guerrero, Michoacan, and other states of the Mexican republic. Together, migratory and immigrant workers and families have created communities of their own, as true bi-national communities that directly link the Mexican population in the region with a number of cities and rural communities in central Mexico.

Today, as before, the transnational migrants travel to and from their communities in Mexico without stopping and working along their journey. They may take a detour and visit kin in other parts of the United States and try their hand at another line of work, often only to return to mushroom harvesting. The men are mainly in their twenties, thirties and forties, and a small number are in their fifties and sixties. Older migrants are married, and it is common for them to work side by side with their sons, who also live in the same housing units. The men, regardless of age, have little or no formal education, and nearly all of them are monolingual Spanish-speakers, which limits their social interaction in local communities.

Transnational Mexican migrants harvest mushrooms on a year-round basis in mushroom production facilities known in the industry as "doubles." These production facilities, scattered throughout the region, are called doubles because the buildings are divided in half, each half independent from the other in terms of environmental conditions, allowing one variety of mushrooms to be grown on one side and another variety on the other side. The facilities are cinder block structures with few windows, rectangular in shape, and measure 8,000 square feet. Their design and construction are ideal for artificially controlling light, temperature, humidity, air circulation and other environmental conditions that are crucial to growing mushrooms. Agaricus mushrooms, the common white button variety sold in grocery stores across the country, account for the majority of the mushrooms produced. However, with each passing year, growers are producing portobellos, shitakes, oysters, and other specialty mushrooms for the regional and national markets $[22,23]$.

Small, quaint boroughs and townships, all with under 6,000 inhabitants, in a semi-rural area characterize this mushroom producing region. Mexican immigrants are concentrated in all of the local communities. In some of the smaller communities (those with less than a thousand inhabitants), according to 2000 census figures, they comprise just under 50 percent of the population. However, the majority of the migrants live in non-traditional housing outside of these communities that differs significantly from their homes in their native Mexico. Their housing mainly consists of employer-owned migrant camps-add-ons (cement cylinder block structures built onto an existing mushroom double) or cottages-and apartments. The camps are situated away from other communities, hidden from public view and unknown to non-Mexican residents. Depending on size, anywhere from six to 42 men reside in the housing compounds. Unlike farm labor camps in other parts of the country, such as those in California or Michigan, where the harvests are seasonal, the residents are not transient. Instead, they share a living unit for months, if not years, and as a result they know each other well. Many are kin, friends, or from the same home community in Mexico. Although they live together, campmates do not form a single household, unless the living arrangement is comprised of immediate kin, for example, a father and his sons. In general, each occupant manages his earnings and pays his own housing expenses, such as rent and food. Nonetheless, as campmates, they share shelter, furnishings, and other amenities, and purchase food and prepare and eat their meals together when time permits.

\section{RESULTS AND DISCUSSION: PARTICIPATORY RE- SEARCH CHALLENGES}

In general, researchers who have engaged in some form of participatory research are aware of its challenges [1-3]. Some of the salient ones are gaining trust and developing rapport among marginalized populations, getting a crosssection of the local community to participate in designing and carrying out the study, and disseminating findings useful to the community [8]. Often, it is only community 
stakeholders or those who are literate that participate in the research enterprise. Those socially marginalized, such as transnational migrants, if they participate in the research, do not do so in the same numbers and are not always seen as full partners by other community members, especially those who feel that they have a greater stake in the local community than a foreign population [8]. Compounding this problem is the conflict that sometimes exists among community leaders and their organizations, which can prevent all of them from rallying around a common cause. Often what happens is that one group will not participate if a rival is involved. These problems are not insurmountable, and their solutions require creativity, community politicking, and more importantly, persistence.

We encountered these problems, as well as others, in our substance abuse studies, but here we limit our attention to the other, less discussed problems. The sensitive nature of the research topic of substance use, coupled with the vulnerability of the transnational migrant population, did not permit a more conventional participatory research approach. We encountered three major limitations, none of which are discussed in the literature. One was safely including the migrant drug user as a collaborator or partner in the research. The second was the general ambivalence of the larger community in the area, including the Mexican immigrant population, toward the health issues of their transnational compatriots. There is a social and cultural divide between transnational migrants, who are relative newcomers and non-permanent residents, and the local Mexican immigrant population, who started to settle in the region three decades ago. The third was the failure to implement program and policy recommendations developed in partnership with community stakeholders.

\section{DRUG USERS AND PARTICIPATION}

In our non-substance abuse studies, immigrant and migrant farmworkers assisted us in developing our research problem, at times redefining it and informing us about how we could best assist them through our research. This same participatory relationship was not possible in our substance abuse studies. The participation of active drug using transnational migrants in community forums, for example, in which they would share their experiences and educate all participants about alcohol and drug abuse, was not possible. The illegal nature of the drug use did not permit it. Many of the drug users preferred to keep their drug use to themselves and to remain anonymous in this regard. They did not want go public with their problems and wanted their drug use to stay confidential, just between them and us. Their reluctance to share their experiences was understandable, given that they did not want their employers and their kin in Pennsylvania and Mexico to know about their substance abuse problems.

Their open participation in participatory research raises human subject concerns that must be considered by the researcher. The drug use of these migrants may become public, which may, in turn, result in a number of serious repercussions for them. It is easier to protect the identity of drug users in traditional ethnographic research than in conventional participatory research, where the identification of the views of individual participants is possible because of the open nature of the participation in the latter approach. Discovery of their drug use behavior and activities may place transnational migrants at risk for criminal sanctions, civil liability, and in many cases deportation [24]. Deportation may keep the migrants and their immediate family members from regularizing their immigration status and entering and staying in the country legally in the future [24]. Others affected by drug use, such as families and friends of drug users, are more open to collaborating as participatory research partners. The families and friends of drug users, for example, are willing to share their insights into the drug use of others. However, they too can be at risk if they participate openly and share their views in community forums, and they too must be protected. Family and kin are vulnerable to verbal and physical retaliation from drug using relatives, and they may be shunned by local community members. At the most extreme, they may not be able to find housing or employment.

The open participation of other community members, such as local Mexican immigrants and mushroom employers, was not as problematic as public involvement of drug users. Unlike migrant drug users, they were not as reluctant to collaborate individually or in group settings and to share what they knew about drug use by migrants and others in the region. These community members and others provided us with useful information that helped us not only to develop but also to implement our research. However, their knowledge of drug use among the transnational migrants was limited, which was not surprising to us. After all, drug use is not public behavior, done in the open, so that everyone can see. Drugs are consumed alone or with other drug users, in private, away from non-users and in locales deemed safe.

\section{COMMUNITY CHALLENGES}

Another challenge to practicing participatory research in our drug studies was a general apathy in the community atlarge regarding the health or plight of the transnational Mexican migrants. Local populations are heterogeneous in regard to ethnicity, religion, citizenship, socioeconomic status, and have different views on Mexican labor migration and immigration to the region. Some community members, those with nativistic perspectives regarding the influx of foreigners, do not reach out to the newcomers. Instead, many of them have voiced their opposition to the "Mexican" presence and blame all Mexicans for most of the local problems, regardless of whether or not they are responsible. Others in the community, particularly employers, labor advocates, and church groups have provided immigrant families with a helping hand and have assisted them in one form or another to settle down and to adjust to their new culture. Still others do not have a strong opinion one way or another.

In general, there is more concern about the drug use problems of the migrant workers among Mexican immigrants in the community, many of whom have migrant kin in area. This is especially the case if the immigrants have their immediate family members with drug problems. However, getting these immigrants that are close to the problem to participate in substance abuse research as collaborators is difficult. A major problem is that often, out of desperation, family members want help for their loved ones immediately, not later, and do not see how they can help them by collaborating in a drug use study. If immediate assistance is not available, they do not see the point of participating in research to 
look for a solution. Another major problem is heavy work schedules that keep immigrants from participating in activities outside of their home or church. Many immigrants are concentrated in low paying employment that pays the minimum wage required by law. To make ends meet, many of them work in more than one job, and when not working, they are tending to their homes and their children. Time spent at work or looking after their family leaves little time for civicminded activities, including participation in political and civic meetings that impact them directly, such as Parent Teacher Association and planning commission meetings.

Another problem in incorporating Mexican immigrants into participatory research aimed at transnational compatriots is an ambivalence that exists toward migrant workers. Migrants, who are mainly solo males that are unaccompanied by family members, are not always welcomed in communities. In neighborhoods, for example, migrants, especially young men who are grouped into an apartment or singlefamily house, are not always accepted. The immigrants see the migrants as transient, loud and unruly, and potentially disruptive, unless they happen to be related to them. Likewise, the migrants also feel uncomfortable interacting with the immigrant population, unless they are kin or close friends. Despite the cultural affinity between immigrants and migrants, and in many cases, a kinship relationship, the two groups are not alike and do not share the same worldview. Immigrants are undergoing different levels of acculturation, learning to speak English, and have a different reason for living in the region. They are setting roots and, consciously and unconsciously, severing their ties to their Mexican hometowns. Migrants, on the other hand, are in the area to earn money and return home to family and community in Mexico. They do not leave their hometowns to become part of another community in the United States. The migrants remain rooted in their homeland, and view their stay in Pennsylvania as temporary.

\section{COMMUNITY STAKEHOLDERS AND PARTICIPA- TION}

There were challenges in establishing a participatory research relationship with non-governmental community-based organizations that work with the local Mexican population and other stakeholders, such as growers. We found it difficult to obtain their collaboration in the research enterprise. For example, directors and staff of the community based organizations were not accustomed to having researchers invite them to join research projects as research partners. In the past, their role, as far as local research was concerned, was limited to making community contacts for the researchers and participating as research subjects. We learned that many were not familiar with the research process and did not feel comfortable making suggestions as to what needed to be studied and how to go about investigating the problem. They also had limited knowledge of drug abuse among the transnational migrants, which often consisted of anecdotal stories of drug arrests and drug-related accidents. We later discovered that they looked to us for information regarding this health problem in their communities.

Despite their unfamiliarity with the problem, nearly all of these stakeholders wanted to help, but they found that time, resource constraints, and heavy demands for their services did not permit it. Community-based organizations, in particular the local community-based organization with a health clinic and a Catholic social service agency, were overwhelmed with the needs of the rapidly growing Mexican immigrant population. The health and social service providers in this mushroom region, similar to many others in the United States with a relatively new and rapidly increasing Mexican population, were unprepared to meet the needs of the new residents. Many of the community-based organizations were finding it difficult to accept new clients or to expand their strained operations to include new services.

Under these conditions, we realized that establishing meaningful research partnerships with community-based organizations require building research capacity among their staff, time to devote to research, and money so that they or others can continue to provide services to the community. Our funding mechanisms did not permit developing these forms of partnership because of strict timelines and tight budgets. Others researchers, such as Israel et al. [6] and Seifer [25], have reached similar conclusions, and propose investing in and building the local community-based research infrastructure to strengthen academic research. This relationship, it is argued, will nurture the development of trust and research collaboration independent of specific research projects, and ensure that the capacity to partner in health research is sustained.

We nonetheless kept a number of stakeholders informed of our research progress during data gathering and analyses, and again sought their assistance towards the end of the project-in development of our research-based recommendations. We worked with several major mushroom producers, a local community-based organization with a health clinic, and a Catholic social service agency that provides an array of social services in the region. We shared our major findings and, at separate meetings with each group, we sought their suggestions in developing recommendations that would help the community at large to address substance abuse among transnational migrants. Coming up with recommendations was no easy task. A major limitation was that the directors and staff members of these organizations did not perceive themselves to be prepared to make recommendations because, as they claimed, they did not have the necessary knowledge regarding drug use among migrants and were inexperienced in developing substance abuse recommendations. However, as we worked through these concerns, they did provide us with suggestions that were included in our research reports.

Working together with community stakeholders, we developed two sets of related recommendations. One set, which we labeled social policy recommendations, focused on situational factors primarily associated with binge drinking and drug abuse. The other set, prevention and intervention program recommendations, had a focus on local prevention and intervention efforts. To formulate social policy recommendations, we took into consideration findings on the underlying cause behind the migrants' substance abuse-their migrant status which places them at risk for illicit drug use. Prevention and intervention recommendations consisted of suggestions for development of new programs, and the strengthening of existing programs in the region. We also suggested that social service providers, governmental agencies, and 
non-governmental community-based organizations alike, should implement these various recommendations.

\section{SOCIAL POLICY RECOMMENDATIONS}

Our social policy recommendations targeted immigration policies, housing rehabilitation and development, transportation, and work schedules. The aim of these recommendations was to address situational factors associated with the migrant status of the transnational workers that contribute to alcohol and drug abuse, such as living situations and social isolation. Specifically, these recommendations called for immigration reform that regularizes or gives legal status to undocumented/illegal migrants, housing development and rehabilitation that alleviates conditions of overcrowding and social isolation, public transportation service to and from the farmworker housing compounds that allows migrants to travel to and participate in community activities and events, and work schedule changes that stabilize irregular work hours and lessen work-related anxiety and stress.

When proposing them, we knew that our social policy recommendations would not be easily implemented, especially since the political climate of the past decade in particular did not favor immigrants and other foreign workers. Nevertheless, employers and non-governmental communitybased organizations agreed that it was important to propose these recommendations. They and other community stakeholders need the support of local voters, who are divided on the issue of whether non-citizens should receive tax-based assistance. The policy recommendations require state and federal legislation, program development, and tax-based funding, all of which are not easy to advocate for or to obtain without a well organized and broad-based political campaign that transcends local communities and includes the voices and efforts of others in the state and throughout the nation.

\section{PREVENTION AND INTERVENTION RECOMMEN- DATIONS}

The next set of recommendations, which we thought were more realistic, primarily dealt with introducing new substance abuse prevention and intervention programs and expanding existing efforts in the community and the region. We had a few county-level governmental offices and nongovernmental community-based organizations in mind as we worked on these recommendations. A couple of them were offices in county-level government responsible for health services and drug programs; one was a non-governmental community-based organization that provides many social services to the local Latino immigrant population, and another was a Catholic social service agency that does the same. The governmental offices, all of them based in the county seat outside of the community, did not take an active role in the development of these recommendations, although their ideas and feedback were occasionally sought. Not all of them were interested in, or had the capacity to participate in, program development. In some cases, they lacked sufficient staff members with the proper training and experience in cross-cultural and substance abuse programming, and in other instances, federal funding restrictions limited the use of their services to citizens and authorized immigrants.

Our major recommendation was that local social service providers offer culturally sensitive and transnational mi- grant-specific programs for substance abuse prevention and intervention. We were unable to recommend any programs designed for transnational migrants-intervention and treatment programs that address the causes at the worksite and homeland and provide services in both countries-because there were none described in the literature or found in practice. However, we did suggest looking into and developing further prevention and intervention measures, some of them practiced by the migrants in both countries. Included in this recommendation was a call to identify financial, structural, and staff constraints that may impede the development and implementation of these and other programs.

One of these programs was sponsored by the mushroom industry, the Alcohol Awareness Program. This now defunct program was designed to educate mushroom workers about the consequences of alcohol and substance abuse through awareness workshops that mainly address how substance abuse adversely affects the body and alters behaviors. These workshops also covered the economic costs of substance abuse-related infractions, such as incarceration, court fees, fines, expensive mandatory alcohol and drug awareness seminars, and loss of income and possibly employment. We suggested evaluating the program, and, if it is found to be successful, expanding it into other parts of the region.

Another was a recently established AA (Alcoholics Anonymous) group, organized by ex-drug using and recovering alcoholic transnational migrants. The regular membership of this AA group was eight workers most of whom were in the country without proper work authorization. Occasionally, membership increased to a dozen or more individuals. As is the case with all AA groups, membership was open to anyone interested in abstinence and turning around their lives, regardless of background. Meetings were held, in Spanish, four times a week, and testimonies centered around labor migration, work, and other areas that have a bearing on the workers' substance use. We suggested registering the group and advertising its services. With our help the group officially registered with the national AA directory and started circulating flyers.

Also among our program suggestions was the juramento, an intervention based on religion and an individual's faith, already in practice in the region through the Catholic social service agency. The juramento, described in detail elsewhere [26], is a cultural and religious practice sanctioned by the Catholic Church to keep parishioners from abusing alcohol and drugs. It is a ritualized pledge or promise made to a saint, often Our Lady of Guadalupe, in the presence of a priest, to abstain from alcohol and drug use for a specific period of time, which usually is six months. Unsubstantiated reports indicate that juramentos show promise, but further examination of the potential of this tradition for deterring substance abuse among transnational migrants is needed [27]. We suggested exploring the effectiveness of the juramento. If this practice is discovered to make a difference in curtailing substance abuse, we proposed expanding and institutionalizing it in other Catholic parishes with a high concentration of transnational Mexican workers.

Our recommendations concluded with a call for coordinating all of the substance abuse prevention and intervention programs aimed at transnational workers in the region in order to provide a more comprehensive and coordinated 
treatment approach. That is, the programs should be working in conjunction with one another, not independently. Effectively preventing and treating binge drinking and drug use requires these partnerships. We did not make concrete suggestions on how to coordinate the prevention and intervention efforts; we only suggested the need to explore how to go about doing this.

Following up on the recommendations, not because it was part of a post-research plan, but because we returned to the site to conduct our current study, we found that our prevention and intervention recommendations, which we believe were much easier to advocate for and to implement than social policies, which required state and federal legislation, were not all adopted, nor were there plans in place for adopting them. We learned that creating new prevention and intervention programs and coordinating them with existing resources was easy to recommend, but difficult to implement without a clear plan. To begin with, as mentioned earlier, there was a dearth of migrant-specific programs designed to curtail substance abuse that could serve as models. Another problem, which was one that we underestimated, was resource constraints on the local social service providers. We knew that social service providers who received federal funding were prohibited from assisting unauthorized workers, but we did not fully realize how limiting this prohibition truly was, especially in offering a substance abuse program plan for these laborers. Another resource issue that we did not anticipate is that many, if not all, of the local governmental agencies or non-governmental organizations have experienced a drastic increase in need for their services, while at the same time undergoing major funding cutbacks, which have forced them to prioritize needs, eliminate or combine staff positions, and restructure programs to meet the needs of as many local residents as possible.

On a positive note, however, we discovered that some employers in the mushroom industry, more so than the social service providers, were in a position to help set up prevention and intervention programs for transnational migrants. In our original recommendations, we suggested including the mushroom industry in program development, but we did not suggest in what capacity, other than advocating for resources. Mushroom producers, particularly large ones, are proactive when it comes to the health of their workforce. They are well aware that worker absenteeism, poor work performance, and work injuries related to substance abuse and other health problems are costly to their businesses in many ways. Many of them belong to a grower committee established over a decade ago to address the needs of mushroom laborers and their families, and to promote the industry locally.

One of the larger mushroom producers in the area, with our assistance, is currently working on establishing low-cost and self-sustaining substance abuse programs. This producer and two other large growers have established clinics in their companies to improve the health of their workers through a number of programs. We currently have been setting-up AlAnon and Alcoholics Anonymous chapters for its employees, many of them transnational workers. These traditional programs, established for the general population, are being offered in the Spanish language and being tailored to include the immigrant and migrant experiences of workers and their families. The mushroom producer involved in this endeavor is providing meeting space, seeking expertise and other resources, and making referrals through its labor relations personnel.

\section{SUGGESTIONS FOR AN IMPLEMENTATION STRATEGY}

The following six measures may be useful in the formulation and implementation of prevention and intervention strategies in participatory and non-participatory research projects:

- Identify and include local governmental agencies and non-governmental community-based organizations in the development of prevention and intervention programs for transnational workers. In doing so, consider their missions or mandates, their targeted clientele, existing programs, and staffing and resource limitations. In addition, efforts should be made to include church or faith-based social service organizations, many of which do not depend on government funding, and, thus, are able to assist non-citizens.

- $\quad$ Efforts should be made to develop the research capacity of the staff of community-based organizations so that staff members can feel comfortable making research suggestions and developing research-based recommendations.

- $\quad$ Employers within the major industries that hire transnational workers should be identified and included as partners in the development and the implementation of substance abuse programs. Programs funded by employers are not constrained by federal mandates, and employers may have resources at their disposal that social service providers do not.

- New and modified prevention and intervention programs should address the causes behind the substance abuse of transnational workers. The transnational nature of this workforce should be taken into account, as should other factors, such as the migrants' length of residence in the region, their work practices and conditions, and their residence patterns and living conditions.

- Social service providers and employers should be assisted in locating and obtaining resources that will help cover the costs of these programs. Because of restrictions that come with government monies, nongovernmental resources should be targeted.

- A follow up plan should be included to verify whether program recommendations were implemented. Such a plan will help researchers to improve future recommendations.

\section{SUMMARY AND CONCLUSION}

There are challenges to using participatory research in substance abuse studies, as we found out, especially if they involve illegal/undocumented transnational migrants. These challenges involve a variety of participants-transnational migrants, the community, and community stakeholders-and limit the use of participatory research in all phases of research, from defining the research problem to collaborating with community stakeholders to develop and propose policy 
and program recommendations. In regard to the latter, an important phase of research, we discovered that it is easy to create a set of recommendations in consultation with community stakeholders, but it is another matter to make them with the confidence that they will be considered and implemented to help those in need. This is a problem in both participatory and non-participatory research. In fact, plans for implementation are not generally part of a research project. In health studies, such as ours, funded by the National Institutes of Health, supplemental funding through additional grants, such as a professional Research Demonstration and Dissemination Grant (NIH R18), is sought for this purpose. The awarding of this grant, however, can take a few years, if one is awarded at all.

The literature provides little guidance in this area. There is no set of common guidelines for formulation and implementation of research recommendations, particularly as they pertain to intervention and treatment, although discussions are currently under way [28]. We made our recommendations in consultation with community stakeholders interested in our work and with colleagues in the substance abuse field. Care was taken to make sure that our recommendations centered on treatment and intervention techniques that addressed underlying causes of substance abuse among transnational migrants, as proposed in our research model, and that they included more immediate action in the areas of prevention and intervention. However, our recommendations were not adopted, and, through inquiries, we identified our implementation mistakes and learned from them, and summarize them in this article.

Based on this experience, we came up with a few measures that are useful in making recommendations, especially in developing and implementing substance abuse prevention and intervention programs for transnational workers. These measures involve identifying community partners, such as church or religious-based organizations, that are not constrained by government funding, a prohibiting factor to providing social services to non-citizens and some immigrants. Employers also are potential partners in substance abuse program development. They have an interest in their workers, and they have more resources at their disposal than do social service providers. Among these measures, there is a need to identify funding sources especially non-federal monies and, if possible, help these social service providers with technical assistance to obtain the funds to implement the programs and interventions. Low cost programs in the community, such as Alcoholics Anonymous and juramentos, should be considered in planning. Lastly, we suggest utilizing a follow-up plan to verify whether program recommendations were implemented. This important final measure will help researchers improve their recommendations in the future.

\section{ACKNOWLEDGEMENTS}

We thank Keith Bletzer for his review of our manuscript and suggestions for revision. His recommendations strengthen earlier versions significantly. We also wish to acknowledge our funding from the National Institutes of Health (NIH), which made our research possible. Funded studies on which this article is based include: "Problem Drinking among Migrant Mexican Farmworkers," National
Institute Alcohol Abuse and Alcoholism, Grant \# 1R03 AA12659-01, "Drug Use among Migrant Mexican Farmworkers," National Institute of Drug Abuse, Grant \# R03 DA17915, and "The Origin and Development of Drug Use Among Transnational Mexican Farmworkers," \# 5R01DA019690-03.

\section{REFERENCES}

[1] Green LW, George MA, Daniel M. Study of participatory research in health promotion: review and recommendations for the development of participatory research in health promotion in Canada. Vancouver, British Columbia: Royal Society of Canada, 1995.

[2] Mora J, Diaz DR. Latino social policy: a participatory research model. New York: Haworth Press 2004.

[3] Crabtree SA, Wong CM, Masud F. Community participatory approaches to dengue prevention in Sarawak, Malaysia. Hum Org 2001; 60(3): 281-7.

[4] Cornwall A, Jewkes R. What is participatory research? Soc Sci Med 1995; 41(12): 1667-76.

[5] Garcia V. Critical Ethnography and substance abuse research among transnational Mexican farmworkers. In: Mora J, Diaz DR, Eds. Latino social policy: A participatory research model. New York: Haworth Press 2004; pp. 119-54.

[6] Israel BA, Schulz AJ, Parker EA, Becker AB, Review of community-based research: assessing partnership approaches to improve public health. Annu Rev Public Health Rep 1998; 19: 173-202.

[7] Minkler M. Using participatory action research to build healthy communities. Public Health 2000; 115: 191-7.

[8] Macaulay AC, Gibson N, Freeman W. Participatory research maximises community and lay involvement. Br Med J 1999; 319: 774-8.

[9] Marcus MT, Walker T, Swint JM, et al. Community-based participatory research to prevent substance abuse and HIV/AIDS in African-American adolescents. J Interprof Care 2004; 18(4): 347-59.

[10] Garcia V. Critical ethnography and substance abuse research among transnational Mexican farmworkers. In: Mora J, Diaz DR, Eds. Latino social policy: a participatory research model. New York: Haworth Press 2004; pp. 119-54.

[11] Garcia V. Problem drinking among transnational Mexican migrants: exploring migrant status and situational factors. Hum Org 2008; 67(1): 12-24.

[12] Garcia V. Drug use among transnational Mexican migrants: findings and new directions in research. Paper read at the $68^{\text {th }}$ Annual Meeting of the Society for Applied Anthropology. Memphis, TN, 2008.

[13] Garcia V. Meeting a bi-national research challenge: substance abuse among transnational Mexican farmworkers in the United States. J Rural Health 2007; 23(3): 61-7.

[14] García V, Gondolf E. Transnational Mexican farmworkers and problem drinking: a review of the literature. Contemp Drug Probl 2004; 31(1): 129-61.

[15] Alaniz ML. Mexican farmworker women's perspectives on drinking in a migrant community. Int J Addict 1994; 29: 1173-88.

[16] Chi PSK. The well-being of migrant farmworkers in New York state. Hum Ecol Forum 1989; 17(2): 20-2.

[17] Chi PSK, McClain J. Migrant farmworkers and drinking in rural New York state. J Rural Health 1992; 8: 41-51.

[18] Morales R. Drinking patterns among seasonal agricultural workers, 1982. PhD [Dissertation]. Syracuse (NY). Syracuse University 1985.

[19] Watson J, Mattera G, Morales R, Kunitz S. Alcohol use among migrant laborers in Western New York. J Stud Alcohol 1985; 46: 403-11.

[20] Trotter RT. Mexican-American experience with alcohol: South Texas examples. In: Bennett LA, Ames G. Eds. The American experience with alcohol: contrasting cultural perspectives. New York: Plenum Press 1985; pp. 279-96.

[21] Bletzer K. Onset of substance abuse among transnational and domestic agricultural workers: social relations and place of initiation. Contemp Drug Probl 2004; 3(1), 89-127.

[22] Garcia V. Mexican enclaves in the US Northeast: Immigrant and migrant mushroom workers in Southern Chester County, Pennsylvania, Julian Samora Research Institute Report Number 27, Michigan State University, East Lansing, MI, 1997. 
[23] Garcia V. The mushroom industry and the emergence of Mexican enclaves in Southern Chester County, Pennsylvania, 1960-1990. J Latino Latin Am Stud 2005; 1(4): 67-88.

[24] Garcia V. Bi-national substance abuse research and internal review boards: human subject risks and suggestions for protections. Hum Org 2009; 68(3): 350-7.

[25] Seifer SD. Building and sustaining community-institutional partnerships for prevention research. J Urban Health 2006; 83:9891003.
[26] Garcia V, Gonzalez L. Juramentos and mandas: traditional Catholic practices and substance abuse in Mexican communities of southeastern Pennsylvania. NAPA Bull 2009; 31: 47-63.

[27] Zabicky G, Solis LR. El juramento: maniobra no médica, coadyuvante en el manejo de los sujetos con consume patológico de etanol en Mexico. Rev Salud Ment 2000; 23 (4): 22-7.

[28] Brown P, Brunnhuber K, Chalkidou K, et al. Health research: how to formulate research recommendations. $\mathrm{Br}$ Med J 2006; 333 (7572): 804-9.

(c) Garcia and Gonzalez; Licensee Bentham Open.

This is an open access article licensed under the terms of the Creative Commons Attribution Non-Commercial License (http://creativecommons.org/licenses/by-nc/3.0/) which permits unrestricted, non-commercial use, distribution and reproduction in any medium, provided the work is properly cited. 